\title{
Sporda Mükemmel Performans Ölçeği'nin (PPS-S) Çocuk ve Yetişkin Sporcular için Geçerlik ve Güvenirliğinin İncelenmesi: Kısa Form
}

\author{
Melike ESENTAŞ ${ }^{1}$, Pinar GÜZEL ${ }^{2}$, Özge YAVAŞ TEZ ${ }^{* 3}$ \\ ${ }^{1}$ Manisa Celal Bayar Üniversitesi, Spor Bilimleri Fakültesi. https://orcid.org/0000-0001-8980-5662, \\ ${ }^{2}$ Manisa Celal Bayar Üniversitesi, Spor Bilimleri Fakültesi. https://orcid.org/0000-0001-5982-2816 \\ ${ }^{3}$ Ankara Üniversitesi, Spor Bilimleri Fakültesi. https://orcid.org/0000-0002-1948-1620
}

Orijinal Makale

Gönderi Tarihi: 21.04.2020
Kabul Tarihi: 06.06.2020
DOI: $10.30769 /$ usbd.724680

Online Yayın Tarihi: 30.06.2020

\section{$\ddot{O} \mathbf{z}$}

Araştırmanın amac1; Sporda Mükemmel Performans Ölçeğiecnin (PPS-S) çocuk ve yetişkin sporcular için revize ederek kısa formunun geçerlik ve güvenirliğini test etmektir. Araştırma, 200 yetişkin ve 294 çocuk olmak üzere iki grup üzerinde yürütülmüştür. İlk grup (MPÖ-YS) AFA sonuçları, maddelerin faktör yük değerlerinin .52-.85 aralığında değiştiğini ve toplam varyans \% 52.06'sını karşıladığını göstermiştir. İkinci grup (MPÖ-ÇS) AFA sonuçları maddelerin faktör yük değerlerinin .35.71 aralığında değiştiğini ve toplam varyans \% 32.34'ünü karşıladığını göstermiştir. Doğrulayıcı Faktör Analizi (DFA) sonuçları her iki ölçeğin (MPO-YS ve MPO-ÇS) Türkçe versiyonu da te alt boyut, MPO-YS toplam 6 madde ve MPO-ÇS toplam 5 maddeden oluştuğunu, MPO-YS modelin mükemmel ve yeterli uyum indekslerine ulaştı̆̆ını $(\chi 2 / \mathrm{sd}=2.21, \mathrm{RMSEA}=$ $0.07, \mathrm{GFI}=0.97, \mathrm{AGFI}=0.92, \mathrm{NFI}=0.96, \mathrm{CFI}=0.97, \mathrm{AGFI}=0.92)$ and MPO-ÇS modelin mükemmel uyum indekslerine ulaştığ $(\chi 2 / \mathrm{sd}=1.50, \mathrm{RMSEA}=0.04, \mathrm{GFI}=0.99, \mathrm{AGFI}=0.97, \mathrm{NFI}=0.98, \mathrm{CFI}=0.99, \mathrm{AGFI}=0.97)$ belirlenmiștir.Her iki ölçeğin Cronbach's Alpha iç tutarlık katsayılarının 0.79 (MPÖ-YS) ile 0.74 (MPO-ÇS) arasında değiştiği bulunmuştur. Her iki ölçeğin Spearman Brown ve Guttman korelasyon katsayıları ise MPÖ-YS için (0.83-0.80); MPÖ-ÇS için (0.88-0.82) olarak bulunmuştur. Ortalama varyans (AVE) ve kompozit güvenilirlik (CR) değerleri hesaplanmıştır [PSS-AS için AVE (0.62) ve CR (0.86); PSS-S için AVE (0.64) ve CR (0.85)]. Elde edilen sonuçlara göre, MPÖ-YS 'ein 18-52 yaş sporcuların mükemmel performans düzeylerini belirlemek için kullanılabilecek yeterli psikometrik özelliklere sahip bir ölçme aracı olduğu söylenebilir. MPÖ-ÇS 'ein 7-17 yaş sporcuların mükemmel performans düzeylerini belirlemek için kullanılabilecek yeterli psikometrik özelliklere sahip bir ölçme aracı olduğu söylenebilir.

Anahtar kelimeler: Mükemmel performans, yetişkin sporcu, çocuk sporcu, geçerlik ve güvenirlik.

\section{Validity and Realiability of Turkish Versions of the Performance Perfectionism Scale for Sport (PPS-S) for Adult and Children Athletes: Short Form}

\begin{abstract}
The aim of this study was to test the validity and reliability of the short form to revise for children and adult athletes of the Performance Perfectionism Scale For Sport (PPS-S). The study was carried out on two groups, 200 adults and 294 children. First group (PPS-AS) EFA showed that the factor load values of the items varied between .52 and .85 and covered $52.06 \%$ of the total variance. Second group (PPS-CS) EFA showed that the factor load values of the items varied between .35 and .71 and covered $32.34 \%$ of the total variance. The CFA results showed that the Turkish version of the both scale (PSS-AS and PSSCS) were also consisted of single sub-dimensions, PPS-AS a total of 6 items and PPS-CS a total of 5 items, the model (PSS$\mathrm{AS})$ reached perfect and adequate fit indexes $(\chi 2 / \mathrm{sd}=2.21, \mathrm{RMSEA}=0.07, \mathrm{GFI}=0.97, \mathrm{AGFI}=0.92, \mathrm{NFI}=0.96, \mathrm{CFI}=0.97$, AGFI $=0.92)$ and the model $($ PSS-CS) reached perfect fit indexes $(\chi 2 / \mathrm{sd}=1.50, \mathrm{RMSEA}=0.04, \mathrm{GFI}=0.99, \mathrm{AGFI}=0.97$, $\mathrm{NFI}=0.98, \mathrm{CFI}=0.99, \mathrm{AGFI}=0.97)$ after with the necessary modification procedures. Reliability coefficients of both scales ranged from 0.79 (PPS-AS) and 0.74 (PPS-CS). Split-Half correlation coefficients of both scale were found for PPS-AS (0.83$0.80)$ and for PPS-CS (0.88-0.82). The mean variance (AVE) and composite reliability (CR) values were calculated [(PPS-AS for AVE (0.62), CR (0.86); PPS-CS for AVE (0.64), CR (0.85)]. Results finally indicated that it can be said that PPS-YS is an instrument that has sufficient psychometric properties can be used determine levels to performance perfectionism of athletes aged between 18-52. It can be said that PPS-CS is an instrument that has sufficient psychometric properties can be used determine levels to performance perfectionism of athletes aged between 7-17.
\end{abstract}

Keywords: Performance perfectionism, adult athletes, child athletes, validity and reliability.

*Sorumlu Yazar: Özge YAVAŞ TEZ, E-posta: ozgeyavas@hotmail.com.tr. 


\section{GíRiș}

Bireylerin fiziksel, zihinsel ve ruhen kendilerini iyi hissetmelerine katkı sağlayan unsurlardan bir tanesi de spordur. Spor, bedeni veya zihni geliştirmek amacıyla kişisel veya toplu olarak gerçekleştirilen, bazı kurallara göre uygulanan hareketlerin tümü olarak tanımlanırken (TDK, 2020); bireylerin sağlıklı nesiller yetiştirmek, toplumsal dayanışmayı sağlamak ve toplumun iş veriminin artmasına katkı sağlamak için sporun önemli bir unsur olduğu ifade edilmiştir (Yetim, 2011). Spor, Türkiye'de ve Dünyada bireyler tarafından serbest zaman etkinliği olarak hobi ya da amatör/profesyonel olarak gerçekleştirilmekte ve aynı zamanda bir meslek olarak tercih edilmektedir. Sporu amatör ya da profesyonel olarak; önceden belirlenmiş kurallar doğrultusunda, bireysel veya takım sporları olarak yapan ve bunu meslek haline getirmiş bireylere sporcu denmektedir. Hurley (2011) amatör sporcuyu; maddi bir kazanç beklentisi olmadan spor organizasyonlarına katılım sağlayan, profesyonel sporcuyu ise, spor performansıyla, antrenmandaki çalışması ve müsabakada elde ettiği sonuç karşısında, para veya parasal değeri olan gelir elde eden kişi olarak tanımlarken; bir sporcuya profesyonel sporcu denilebilmesinin ancak sporcu ile spor kulübü arasında bir sözleşme yoluyla olabileceğini ifade etmiştir.

TDK (2020) performansı, başarım olarak ifade etmektedir. Sporcunun seçmiş olduğu ve yapmakta olduğu spor branşında en iyi kademeye ulaşmak için performans sergilemektedir. Sporcuların, mükemmel bir performans sergilemesinde en önemli olan etkenlerden biri de yetenek ve becerilerini artırması için katıldığı antrenmanlar ve mental antrenmanlar aracılığıyla mükemmelliğe ulaşması, hedeflerine ulaşması açısından önem taşıdığ söylenebilir. Sportif performans; yapılması gereken bir atletik görevin yerine getirilmesi sırasında başarı için ortaya konulan çabaların bütünü olarak tarif edilebilir (Ermiş, 2019).

Spor organizasyonlarında çatı niteliği taşıyan ve spor örgütlerinin en üst yapılanması olan Uluslararası Olimpiyat Komitesi (IOC) sporda Olimpik Hareket anlayışını üç temel değer üzerine oturtmuştur. Bu temel değerlerden birisi de mükemmelliyetçiliktir (Guzel ve Ozbey, 2009; Guzel, Ozbey ve Noordegraff, 2012; Guzel ve Ozbey, 2012; Guzel ve Çelebi, 2017; Gutmann, 2002). Bu değer ister oyun alanında isterse profesyonel yaşantıda bireyin yapabildiklerinin en iyisini yapmak anlamına gelmektedir (Guzel ve Ozbey, 2013; Salaheldeen, 2010). Herkes için spor anlayışının temelinde de yatan spor yapan bireylerin mükemmelliğe ulaşma çabası içerisinde ulaşılabilen hedefin kendilerinin en iyi yapabildiğine ulaşmasıdır. $\mathrm{Bu}$ noktada mükemmeliyetçilik, kişinin davranışını aşırı derecede değerlendirilmesine yönelik eğilimlerinin yanı sıra kusursuz bir performans sergilemek için yüksek standartlar belirlemek ve çabalamak ile karakterize edilen kişilik özelliği olarak görülürken (Flett and Hewitt, 2002); bazı araştırmacılar mükemmeliyetçiliği kişinin hedefindeki performansa ulaşmaya yardımcı olabilecek uyarlanabilir bir özellik olarak görmektedir (Gould, Dieffenbach and Moffett, 2002).

Araştırmacıların pozitif bir kişilik özelliği olarak yorumladığı mükemmeliyetçilik, bazı araştırmacılar tarafından da mükemmel performansı olumsuz yönde etkileyen ve engelleyen "mükemmeliyetçilik paradoksu" olarak adlandırılan uyumsuz bir özellik olarak görmektedir (Flett and Hewitt, 2005). 
Birçok insan yaşamının her alanında mükemmel olma ya da mükemmele ulaşma isteği duyar ve bu spor alanı için ayrı bir önem taşır. Özellikle rekabete dayalı sporlarda sporcular kendi kulvarı içerisinde bir madalya kazanmak, rekor kırmak ve en önemlisi de belki de tanınmak ister. $\mathrm{Bu}$ arzularına ulaşmak içinde sporcular en az hata ile mükemmel olma yolunda ilerlerler.

Spor ortamında her ne kadar sporcuların mükemmel performans göstermeleri beklensede rekabet ortamında kaygının oluşması sporcuların elde etmek istediği performansın engellemesini tetikleyebilir (Flett and Hewitt, 2005). Diğer taraftan mükemmeliyetçilik, çok boyutlu ve çok yönlüdür. Bazı boyutlar ve yönler negatif, zararlı ve uyumsuz olarak görülebilecekken; bazıları pozitif, iyi huylu ve uyarlanabilir bir özellik olarak değerlendirilebilir (Chang, 2003; Enns and Cox, 2002). Mükemmeliyetçiliğin negatif olarak değerlendirilen boyutu; performansa ilişkin hataların, endişelerin ve davranışlarda tereddüt etme ile karakterize edilen ve bu yönde kişinin beklentileri ile performansa ilişkin sonuçlar arasında tutarsızlık oluşturan yönüyle ilişkilidir ve bu boyut daha çok kaygı gibi olumsuz özelliklerle ilişkilendirilmiştir. Bunun aksine, mükemmeliyetçiliğin pozitif olarak değerlendirilen boyutu; performansa ilişkin kişinin yüksek standartlara sahip olması ve buna ulaşmak için öz-kontrollü olmakla ilişkilidir (Bieling, Israeli ve Antony, 2004; Hill and et al., 2004; Suddarth and Slaney, 2001). Spor içerisinde oluşan rekabet ortamı da bireyleri mükemmellik yoluna sürüklerken bu durum onlarda olumlu ya da olumsuz etki yaratabileceği unutulmamalıdır.

Yurtiçi ve yurtdışı alanyazın incelendiğinde çalı̧̧malarda sporun psikososyal, fiziksel, zihinsel, sağlı ve yaşam kalitesi açısından olumlu katkıları üzerinde durulduğu görülmeketedir (Küçük ve Koç, 2004; Yiyit, 2017; Snedden et al., 2019; Jones et al., 2020). Mükemmelliyetçiliğin çok yönlülüğü ile ilişkili olarak yurtdışında dışında geliştirilen ölçme araçlarının ve çalışmaların çoğunlukta olduğu ancak yurtiçinde bu çalışmaların sınırlı sayıda olduğu dikkat çekmektedir. Özellikle yurtiçi çalışmalarda geliştirilen ve uyarlanan ölçme araçlarının ise sporcuların ve antrenörlerin duygu durumları ve yeterlilikleri ile ilgili olduğu da belirlenirken (Osman ve Aşçı, 2019; Aşç1, Çağlar, Eklund, Altıntaş ve Jackson, 2007; Unutmaz ve Gençer, 2017); Sporda mükemmeliyetçilik ile ilgili çalışmalarda "Spora Özgü Çok Boyutlu Mükemmeliyetçilik Ölçeğì" (The Sport Multidimensional Perfectionism Scale) kullanılmaktadır (Çepikkurt ve Yazgan, 2012; Gözmen ve Aşçı, 2016; Gümüşoğlu ve Aşçı, 2020; Kocadağ, 2019; Kurudirek, 2017; Özdemir, 2019). Söz konusu ölçeğin (Spora Özgü Çok Boyutlu Mükemmeliyetçilik Ölçeği) Çepikkurt (2011) tarafindan Türkçeye uyarlama çalışması yapıldığı ancak çalışmada ölçeğe ilişkin yapı geçerliği aşamaları gerçekleştirilmediği tespit edilmiştir. Bu durum ölçek geliştirme ve uyarlama çalışmalarında ölçeğin kültür için geçerli ve güvenilir bir ölçme aracı olarak kullanılmasını sıkıntıya sokarken ölçeğin yapı geçerliği çalışması yapılmadığı için geçerli bir ölçme aracı olup olmadığı noktasında bir soru işareti bırakmaktadır.

Bir diğer önemli noktada spor bilimleri alanın ölçme araçlarının kullanımlarında, ölçme araçlarının uzunluğu araştırmacıları uygulama aşamasında sıkıntıya sokmakta ve sağlıklı 
olmayan sonuçların elde edilmesine neden olmaktadır. Bu da araştırmacıları için zaman, emek ve hatta ekonomik açıdan zarara uğratmaktadır. Yakın tarihli yurtiçi ve yurtdışı ölçme araçları ile ilgili literatür taraması yapıldığında büyük bir çoğunluğunun ölçme araçlarının kısa formu üzerinde uyarlama ve ölçme aracı geliştirme çalışmalarının düşük olduğu görülmektedir. Bu çalışmaların içerikleri incelendiğinde lisans ve lisansüstü öğrencilerin ve araştırmacıların çalışmalarında daha çok kısa formlu ölçme aracını tercih ettikleri dikkat çekmektedir. Kısa Ölçme araçları, zaman sınırlılığı, uygulama kolaylığı, tarama amaçlı, çocuklar için kullanım ve yapısal eşitlik gibi çok değişkenli araştırmalar için tercih edilmektedir. Belirtilen bu yararlar kısa ölçme araçlarını araştırmacılar tarafından daha çok tercih edilir hale getirmektedir. Özellikle ölçeğin kısa ve kolay uygulanabilir bir formunun oluşturulması spor bilimleri alanındaki araştırmacıların önemli bir ihtiyacını karşılayacağı düşünülmektedir. Bu doğrultuda araştırmada, Hill, Appleton and Mallinson (2016) tarafindan geliştirilen Sporda Mükemmel Performans Ölçeği'ni (PPS-S) Türkçeye uyarlama çalışması yapılarak ve ölçeğin hem yetişkin hem de çocuk sporcular için kısa bir formunun geçerlik ve güvenirlik çalışmasının yapılması amaçlanmıştır.

\section{YÖNTEM}

Araştırma Modeli: Araştırmada evreni en iyi temsil edebileceği düşünülen bir grup ile çalışma imkanı sağlayan ve bu yönde tüm evren hakkında bilgi edinmeyi kolaylaştıran nicel araştırma yöntemlerinden birisi olan genel tarama modeli kullanılmıştır (Krathwohl, 1997; Karasar, 2012).

Araştırma Grubu: Araştırmada PPS-S'ye ilişkin çocuk ve yetişkin olmak üzere iki ölçüm aracı uyarlamak istenildiği için iki örnek grubu üzerinde işlemler yürütülmüştür. Araştırma evreni Türkiye'de yer alan çeşitli spor komplekslerindeki katılımcılar oluşmaktadır. Araştırmanın örneklem grubu çocuk ve yetişkin olmak üzere iki grup altında oluşturulmuştur. Araştırmada yaş gruplarının çocuk ve yetişkin olarak ayrılmasında Dünya Sağlık Örgütü’nün belirlemiş̧ olduğu yaş aralıkları dikkate alınmıştır (WHO, 2015). Bu doğrultuda ilk grubu (çalışma 1); yaşları 18-52 arasında değişen çeşitli kategorilerde (cimnastik, yüzme, karate, kickbox, güreş, tenis, bisiklet, futbol, voleybol, basketbol) yer alan 200 yetişkin (kadın=102; yaş=23,36 $\pm 6,55$ y1l; erkek $=98$; yaş=24,86 $\pm 9,42$ ) oluşturmuştur. İkinci grubu (çalışma 2 ) ise yaşları 7-17 arasında değişen çeşitli kategorilerde (cimnastik, yüzme, karate, kickbox, güreş, tenis, bisiklet, futbol, voleybol, basketbol) yer alan 294 çocuk ( $\mathrm{k} 1 \mathrm{z}=186$; yaş=12,88 $\pm 2,37$; erkek=108; yaş=12,64 $\pm 2,85$ ) oluşturmuştur.

\section{Veri Toplama Aracı}

Sporda Mükemmel Performans Ölçeği (PPS-S): Ölçek, Hewitt ve Flett'in (1991) mükemmeliyetçiliğin boyutları ile ilgili ortaya konulan modelden esinlenerek Hill, Appleton ve Mallinson (2016) tarafından geliştirilen bir ölçektir. Ölçek kendine yönelik performans mükemmeliyetçiliği (SOPP), sosyal olarak belirlenmiş performans mükemmeliyetçiliği (SPPP) ve diğerlerine yönelik performans mükemmeliyetçiliği (OOPP) olmak üzere 3 alt 
boyut ve 12 maddeden oluşmaktadır. Kendine yönelik performans mükemmeliyetçiliği (SOPP), bireyin kendisi için belirlediği yüksek standartlardır. Ancak kişinin belirlemiş olduğu bu standartlara ulaşması imkansızdır. Bu kişiler ya hep ya da hiç mantığında hareket ederek eleştiri ve hataları asla kabul etmezler ve hata yapacaklarından sürekli endişe duyarlar. Mükemmel bir performans sergilemeye odaklıdırler ve bu noktada başkalarının başarısız performanslarını da küçümserler. Sosyal olarak belirlenmiş performans mükemmeliyetçiliği (SPPP), mükemmliyetçiliğin bireysel değil kişiler arasındaki etkileşimini açıklar. Birey başka insanların beklentilerini karşılamak ve onlardan onay almak için mükemmel bir performans sergilemek için uğraşırlar. Bu kişiler başkaları tarafından yönlendirilir ve bu duruma karşı koyamayacaklarına inanırlar. $\mathrm{Bu}$ nedenle, kendisi için belirlenen standartları karşılayamadıklarında bu kişilere karşı öfke duyarken başarısız bir sonuçla karşılaştıkları için de depresyona girerler. Diğerlerine yönelik performans mükemmliyetçiliği (OOPP), bireyin kendisi için değil bu sefer başkalarına yönelik yüksek standartlar belirler ve bu standartlara uyum göstermelerini bekler. Başkalarının olumsuz performanslarına karşı standartları belirleyen kişiler hayal kırıklığı, stres ve öfke duygusu yaşar ve bir daha görev vermekten kaçınırlar. Kişi başkalarına karşı otoriter ve kontrol odaklı davranarak adete düşmanca davranışlar sergiler (Hewitt and Flett, 1991). Ölçeğin derecelendirilmesinde (1) kesinlikle katılmiyorum (2) katılmıyorum, (3) kısmen katılmıyorum , (4) kararsızım, (5) kısmen katılıyorum, (6) katılıyorum, (7) kesinlikle katılıyorum olmak üzere 7'li Likert tipi bir derecelendirme sistemi kullanılmıştır.

Veri Toplama Süreci ve Analizi: PPS-S'nin Türkçe'ye uyarlanması sürecinde öncelikle ölçeği geliştirenlerden ilk isim olan Hill A.P., ile bağlantıya geçilmiş, kendi kültürümüze çeviri ve uyarlama için izin istenmiştir. Gerekli izin alındıktan sonra ölçeğin yetişkin ve çocuk sporcular üzerinde geçerlik ve güvenirlik çalışmaları için adaptasyon çalışmalarının ilk aşaması olan ölçeğin dilsel eşdeğerlik çalışması gerçekleştirilmiştir. Dilsel eşdeğerlik çalışmasında ölçekte yer alan her bir ifade kaynak dilden-hedef dile çevrilmiş ve bütün formlar hakem değerlendirme formuna aktarılarak spor bilimleri alanında uzman kişiler tarafından değerlendirilerek Türkçe form oluşturulmuştur. Türkçe forma ilişkin dil ve anlatım kontrolü sonrasında oluşturulan form küçük bir gruba uygulanmıştır. Oluşturulan Türkçe form ile birlikte katılımcıların demografik özelliklerinin belirlenmesi amacı ile oluşturan kişisel bilgi formu elektronik ortama aktarılmış ve online form hazırlanmıştır. Bu doğrultuda oluşturulan form alanda uygulanmıştır. Daha toplanan verilerin analiz işlemlerine geçilmiştir. Ölçeğin yapı geçerliğini test etmek için Spss ve Amos programları kullanılmıştır. Ölçeğe ilişkin yapı geçerliği analizlerine geçilmeden önce madde analizleri ve veri setinin faktör analizine uygunluk analizleri yapılmıştır. Daha sonra SPSS 24. programı kullanılarak AFA (Açımlayıcı Faktör Analizi) yapılarak ölçeğin kendi kültürümüz için hangi yapıda olduğu belirlenerek yapının doğrulanması için DFA (Doğrulayıcı Faktör Analizi) yapılmıştır. Geçerlik çalışmasından sonra MPÖ’nin iç tutarlılık güvenirliği için Cronbach Alfa değerleri ve iki yarı test güvenirliği (Split-Half), yakınsak geçerlik için Açıklanan Ortalama Varyans (AVE) ve Yapı Güvenirliği (CR) değerleri hesaplanmıştır. 


\section{BULGULAR}

\section{Çalışma 1}

\section{Mükemmel Performans Ölçeği-Yetişkin Sporcular (MPÖ-YS) için Madde Seçimi Analizleri}

Madde seçimi için ölçeğe ilişkin madde-toplam güvenirlik değerlerine bakılmıştır. Bunun için Field (2009) tarafından belirtilen eleme ölçütü $(0.30 \leq \ldots)$ dikkate alınmıştır. Yetişkin sporcular için toplanan verilerin madde analizi işleminde her bir maddeye ilişkin korelasyon değeri incelenmiştir. Analiz sonucunda madde 3 (.20), madde 5 (.19), madde 2 (.21), madde 1 (.17), madde $6(.26)$ ve madde 4 (.15) sinır değer olarak belirlenen $(0.30 \geq \ldots)$ değerden düşük olması sebebi ile ilgili maddeler AFA analizine geçilmeden önce ölçekten çıkarılmış ve toplam 6 madde ile AFA yapılmıştır.

\section{Yapı Geçerliği}

MPÖ-YS'nin yap1 geçerliği için öncelikle verilerin faktör analizine uyguluğunun denetlenmesi gerekmektedir. Bunun için ilgili veri seti SPSS 24.00 programında verilere ilişkin KMO (Kaiser-Meyer-Olkin) ve Barlett Sphericity testleri yapılmıştır. Yapılan işlemler sonucunda yetişkin sporcular için toplanan veri setine ilişkin KMO değeri 0.76 ve Barlett test değeri ise 438,729 $(\mathrm{p}<.001 . \mathrm{sd}=15)$ olarak bulunmuştur. $\mathrm{Bu}$ değerler veri setinin faktör analizi için uygun olduğunu göstermiştir (Field. 2009). Bu işlemler sonrasında MPÖ-YS'nin Açımlayıcı Faktör Analizi (AFA) aşamasına geçilmiştir. Açımlayıcı Faktör Analizi (AFA) analiz sonucu Tablo 1'de sunulmuştur.

Tablo 1. MPÖ-YS'nin faktör yapısı ve faktör yükleri

\begin{tabular}{|c|c|c|c|}
\hline$n=200$, madde no & Madde Içerik & $M A \ddot{O}-Y S$ & $\begin{array}{c}\text { Faktörlerin } \\
\text { Açıkladığı } \\
\text { Varyans } \\
(\%)\end{array}$ \\
\hline MPÖ-YS_11 & (İnsanlar mükemmel performans göstermediğinde onları eleştiririm.) & ,85 & \\
\hline MPÖ-YS_12 & $\begin{array}{c}\text { (İnsanlar mükemmel performans göstermediğinde onlar hakkında } \\
\text { olumsuz düşünürüm.) }\end{array}$ & ,83 & \\
\hline MPÖ-YS_9 & $\begin{array}{l}\text { (Diğerleri mükemmel performans göstermediğinde onlar hakkında } \\
\text { olumsuz düşünürüm.) }\end{array}$ &, 81 & $\% 52.06$ \\
\hline MPÖ-YS_10 & (Diğerlerinin performanslarından asla tatmin olmam.) & ,68 & \\
\hline MPÖ-YS_7 & (İnsanlar en iyi performansımı bile olumsuz olarak görür.) &, 54 & \\
\hline MPÖ-YS_8 & (Mükemmel performans göstermediğimde insanlar beni eleştirir.) &, 52 & \\
\hline
\end{tabular}

Tablo 1'de veri setine ilişkin gerçekleştirilen faktör analizi sonuçları yer almaktadır. Buna göre 200 yetişkin sporcu ile gerçekleştirilen AFA sonuçları incelendiğinde maddelerin faktör yük değerlerinin “.52 -.85” aralığında değiştiği görülmektedir. Maddelerin açıkladığı varyans \% 52.06 olduğu belirlenmiştir. Bu sonuçlar MPÖ-YS'nin tek faktörlü yapıyı desteklediğini göstermiştir. Böylece MPÖ-YS için altı maddelik tek faktörlü yapının doğrulanması için Doğrulayıcı Faktör Analizi (DFA) yapılmıştır. Tek faktörlü yapıya ilişkin Doğrulayıcı Faktör Analizi (DFA) sonuçlarının yorumlanmasında genel kabul görmüş uyum indekslerine dikkate alınmıştır. 

18-34.

Aşağıda MPÖ-YS modelline ilişkin yol diagramları, uyum indeksleri ve modellere ilişkin değerler Şekil 1 ve Tablo 2'de sunulmuştur.

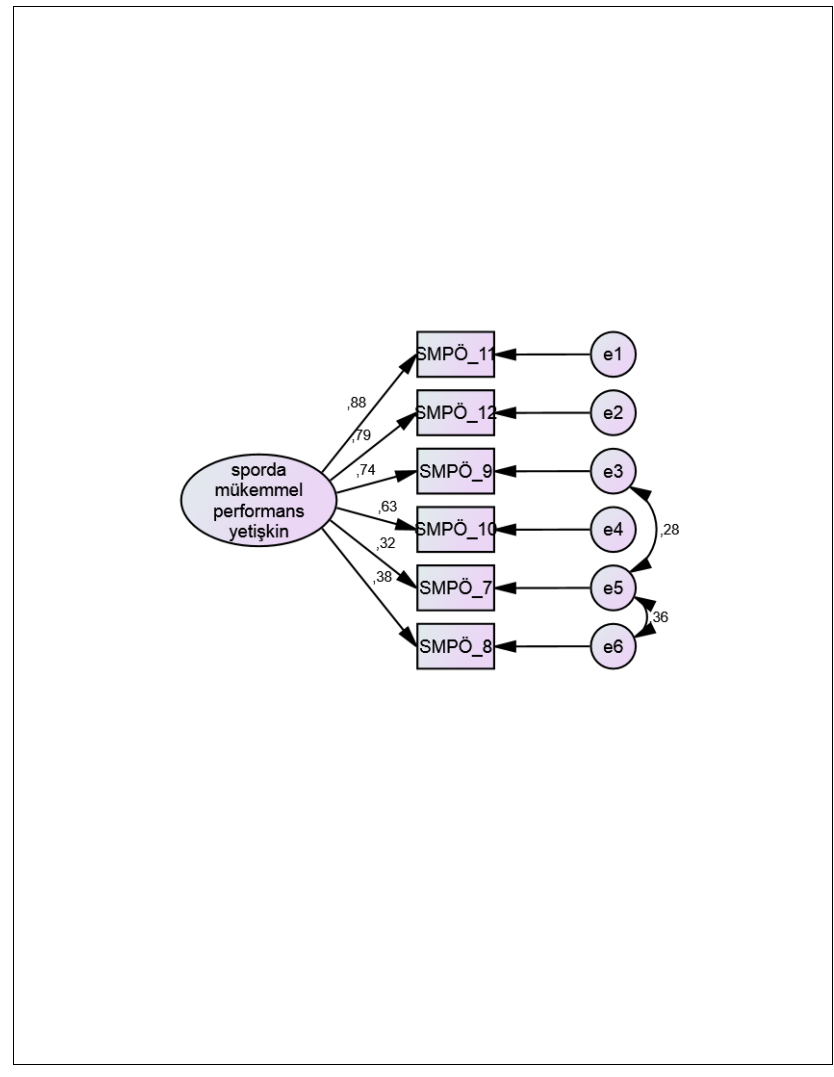

Şekil 1. MPÖ-YS’nin yol diagramı

Tablo 2. MPÖ-YS'nin uyum indeksleri ile standart uyum değerleri (Schumacher ve Lomax, 1996; Schermelleh, Engel ve Moosbrugger, 2003: 23-74).

\begin{tabular}{l|ccc}
\hline Uyum İndeksi & Mükemmel Uyum & $\begin{array}{c}\text { Kabul Edilebilir } \\
\text { Uyum }\end{array}$ & $\begin{array}{c}\text { MAÖ-YS } \\
\text { Uyum İndeksleri }\end{array}$ \\
\hline $\mathbf{x}^{2} / \mathbf{s d}$ & $0-3$ & $3-5$ & $\mathbf{2 . 2 1}$ \\
CFI & $.95 \leq \mathrm{CFI} \leq 1.00$ & $.90 \leq \mathrm{CFI}<.95$ & $\mathbf{. 9 8}$ \\
GFI & $.90 \leq \mathrm{GFI} \leq 1.00$ & $.85 \leq \mathrm{GFI}<.90$ & $\mathbf{. 9 7}$ \\
AGFI & $.90 \leq \mathrm{AGFI} \leq 1.00$ & $.85 \leq \mathrm{AGFI}<.90$ & $\mathbf{. 9 2}$ \\
NFI & $.95 \leq \mathrm{NFI} \leq 1.00$ & $.90 \leq \mathrm{NFI}<.95$ & $\mathbf{. 9 6}$ \\
TLI & $.90 \leq \mathrm{TLI} \leq 1.00$ & $.85 \leq \mathrm{TLI}<.90$ & $\mathbf{. 9 5}$ \\
RMSEA & $.00 \leq \mathrm{RMSEA} \leq .05$ & $.05<\mathrm{RMSEA} \leq .10$ & $\mathbf{. 0 7}$ \\
\hline
\end{tabular}

Tablo 2 incelendiğinde MPÖ-YS'nin uyum indeksleri, standart uyum indeksleri ile karşılaştırıldığında MPÖ-YS'ye ilişkin sonuçların mükemmel ve kabul edilebilir değer aralıkları içerisinde olduğu belirlenmiştir. MPÖ-YS'ye ilişkin maddelerin faktör yük değerlerinin .31 ile .88 arasında değiştiği görülmektedir. Buna göre MPÖ-YS'nin 6 maddelik azaltılmış madde sayısı orijinal formdan farklı olarak tek faktörlü yapıyı desteklediği ve yetişkin sporcular için tek faktörlü yapısının Türk örnekleminde doğrulandığı belirlenmiştir. 
Ayrıca MPÖ-YS'nin madde-toplam korelasyonları, yakınsak ve ıraksak geçerlik için Açıklanan Ortalama Varyans (AVE), Açıklanan Ortalama Varyansın Karekökü ( AVE) ile Yapı Güvenirliği (CR) değerleri hesaplanmıştır. Analiz sonuçları Tablo 3'de sunulmuştur.

Tablo 3. Mükemmel Performans Ölçeği Yetişkin Sporcular (MPÖ-YS) için gerçekleştirilen dfa sonucuna göre faktör korelasyon ilişkisi, faktörler arası korelasyon değerlerinin karesi, AVE, $\sqrt{ }$ AVE ve CR değerleri

\begin{tabular}{|c|c|c|c|c|c|c|c|c|c|c|c|}
\hline & & 1 & 2 & 3 & 4 & 5 & 6 & 7 & AVE & $\sqrt{ } \mathbf{A V E}$ & CR \\
\hline 1.MPÖ-YS-11 & $\mathbf{r}$ & 1 &, $685^{* *}$ & $643^{* *}$ & ,569** & $251^{* *}$ &, $378^{* *}$ &, $812^{* *}$ & & & \\
\hline 2.MPÖ-YS-12 & $\mathbf{r}$ & & 1 &, $631^{* *}$ &, $483^{* *}$ &, $349^{* *}$ &, $274^{* * *}$ &, $787^{* *}$ & & & \\
\hline MPÖ-YS-9 & $\mathbf{r}$ & & & 1 & $449^{* * *}$ & $400^{* *}$ &, $231^{* *}$ &, $782^{* * *}$ & & & \\
\hline 4.MPÖ-YS-10 & $\mathbf{r}$ & & & & 1 &, $171^{*}$ &, $208^{* *}$ &, $681^{* *}$ & & & \\
\hline 5.MPÖ-YS-7 & $\mathbf{r}$ & & & & & 1 &, $420^{* * *}$ & $623^{* *}$ & 0.62 & 0.79 & 0.86 \\
\hline 6.MPÖ-YS-8 & $\mathbf{r}$ & & & & & & 1 &, $588^{* *}$ & & & \\
\hline 7.MAÖ-YS & $\mathbf{r}$ & & & & & & & 1 & & & \\
\hline TOPLAM & & & & & & & & & & & \\
\hline
\end{tabular}

**p $<0.01, * \mathbf{p}<0.05$

Tablo 3 incelendiğinde MPÖ-YS'ye ilişkin madde-toplam korelasyon, Açıklanan Ortalama Varyans (AVE) ve Yapı Güvenirliği (CR) değerleri verilmiştir. MPÖ-YS'ye ilişkin maddetoplam korelasyon katsayısının 0.58 ile 0.81 arasında görülmektedir. MPÖ-YS'ye ilişkin AVE değeri 0.62 , $\sqrt{ }$ AVE değeri 0.79 ve CR değeri 0.86 olarak hesaplanmıştır. Literatürde AVE değerinin $(0.50<\ldots)$ ve CR değerinin $(0.70<\ldots)$ olması beklenmektedir (Hair ve diğ., 2009).

Literatürde 1raksak geçerlik için benimsenen yaklaşım ölçüm modelinde yer alan korelasyon değerlerinin 0.90'nın üzerinde olmaması gerektiği (Kline, 2010) ve bu değerlerin hesaplanmasının ise AVE değerinin karekökü alınarak ortaya çıkan değerin korelasyon katsayılarından daha yüksek olması gerektiği ifade edilmiştir (Fornell and Larcker, 1981). Bu doğrultuda MPÖ-YS'nin rraksak geçerlik değerlerinin kriter olarak belirlenen 0.90 değerinin altında olduğu belirlenmiştir. Buna göre yapılan hesaplamalar sonrasında ölçeğe ilişkin AVE ve CR değerlerinin minimum eşik sınırı değerlerinin üstünde ve AVE değerinin karekökünün ise maksimum eşik sınırı değerlerinin altında olması ölçüm modellinin kabul edilebilir düzeyde yakınsak ve ıraksak geçerliğe sahip olduğunun kanıtı niteliğindedir.

\section{Güvenirlik}

MPÖ-YS'nin güvenirliği için iç tutarlılık katsayıları Cronbach Alpha ve iki yarı test güvenirlik (Split-Half) yöntemleriyle hesaplanmıştır. Literatürde Büyüköztürk (2010) tarafından Cronbach Alpha güvenirlik katsayısının 0.70 ve üzerinde olmasının ölçek güvenilirliği için yeterli kabul edilebileceği ifade edilmiştir. Bu doğrultuda MPÖ-YS için Alpha katsayısı 0.79 olarak hesaplanması ölçme aracının güvenilir olarak kabul edilebileceğini göstermiştir. Araştırmada zaman ve uygulama kolaylığg açısından iki yarı test güvenirliği tercih edilmiş ve bu doğrultuda ölçek maddeleri rastlantısal şekilde ikiye ayrılarak formül yardımıyla $[r$ Test $=(2 r / 1+r) ; r=$ testin yarısına ait korelasyon katsayısı] güvenirlik katsayısı hesaplanmıştır (Seçer, 2013). Bu doğrultuda MPÖ-YS’nin Spearman-Brown değeri 0.83 ve Guttman değeri 0.80 olarak hesaplanmıştır. Bu değerler bize her ölçeğin kabul 
Esentaş, M., Güzel, P., ve Yavaş Tez, Ö. (2020). Sporda Mükemmel Performans ölçeği'nin (PPS-S) çocuk ve yetişkin sporcular için geçerlik ve güvenirliğinin incelenmesi: Kısa form. Ulusal Spor Bilimleri Dergisi, 4(1), 18-34.

edilebilir düzeyde ve güvenilir olduğunu göstermektedir. Analiz sonuçları Tablo 4'de sunulmuştur.

Tablo 4. Altı maddelik MPÖ-YS'nin iç tutarlık (Cronbach Alpha) ve iki yarı test (Split-Half) güvenirlik değerleri, madde numaraları ve içerikleri

\begin{tabular}{|c|c|c|c|c|}
\hline & Madde Numaraları ve İçerikleri & $\begin{array}{l}\text { Spearman- } \\
\text { Brown }\end{array}$ & Guttman & 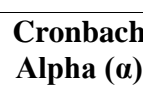 \\
\hline $\begin{array}{c}\text { Mükemmel } \\
\text { Performans Ölçeği- } \\
\text { Yetişkin Sporcular } \\
\text { (MPÖ-YS) } \\
(\mathbf{7 , 8 , 9 , 1 0 , 1 1 , 1 2 )}\end{array}$ & $\begin{array}{l}\text { MPÖ-YS-11 (İnsanlar mükemmel performans göstermediğinde onları } \\
\text { eleştiririm.) } \\
\text { MPÖ-YS-12 (İnsanlar mükemmel performans göstermediğinde onlar } \\
\text { hakkında olumsuz düşünürüm.) } \\
\text { MPÖ-YS-9 (Diğerleri mükemmel performans göstermediğinde onlar } \\
\text { hakkında olumsuz düşünürüm.) } \\
\text { MPÖ-YS-10 (Diğerlerinin performanslarından asla tatmin olmam.) } \\
\text { MPÖ-YS-7 (İnsanlar en iyi performansımı bile olumsuz olarak görür.) } \\
\text { MPÖ-YS-8 (Mükemmel performans göstermediğimde insanlar beni } \\
\text { eleştirir.) }\end{array}$ & 0.83 & 0.80 & .79 \\
\hline
\end{tabular}

$\boldsymbol{\alpha}:$ Altı maddelik MPÖ-YS'nin Cronbach Alpha $(\alpha)$ değeri

\section{Çalışma 2}

\section{Mükemmel Performans Ölçeği-Çocuk Sporcular (MPÖ-ÇS) İçin Madde Seçimi Analizleri}

Madde seçimi için ölçeğe ilişkin madde-toplam güvenirlik değerlerine bakılmıştır. Bunun için Field (2009) tarafindan belirtilen eleme ölçütü $(0.30 \leq \ldots)$ dikkate alınmıştır. Çocuk sporcular için toplanan verilerin madde analizi işlemleri için her bir maddeye ilişkin korelasyon değeri incelenmiştir. Yapılan analiz sonucunda madde 3 (.09), madde 4 (.17), madde 5 (.21), madde 6 (.15), madde 7 (.19) ölçekten çıkarılmış ve böylece toplam 7 madde ile AFA gerçekleştirilmiştir.

\section{Yapı Geçerliği}

MPÖ-ÇS'nin yap1 geçerliği için öncelikle verilerin faktör analizine uyguluğunun denetlenmesi gerekmektedir. Bunun için ilgili veri seti SPSS 24.00 programında verilere ilişkin KMO (Kaiser-Meyer-Olkin) ve Barlett Sphericity testleri yapılmıştır. Yapılan işlemler sonucunda çocuk sporcular için toplanan veri setine ilişkin KMO değeri 0.73 ve Barlett test değeri ise 838,73 $(\mathrm{p}<.001 . \mathrm{sd}=45)$ olarak bulunmuştur. Bu değerler veri setinin faktör analizi için uygun olduğunu göstermiştir (Field, 2009). Bu işlemler sonrasında MPÖ-ÇS'nin Açımlayıcı Faktör Analizi (AFA) aşamasına geçilmiştir.

Açımlayıcı Faktör Analizi (AFA) analiz sonucu Tablo 5'te sunulmuştur. 
Esentaş, M., Güzel, P., ve Yavaş Tez, Ö. (2020). Sporda Mükemmel Performans ölçeği’nin (PPS-S) çocuk ve yetişkin sporcular için geçerlik ve güvenirliğinin incelenmesi: Kısa form. Ulusal Spor Bilimleri Dergisi, 4(1), 18-34.

Tablo 5. MPÖ-ÇS’nin faktör yapısı ve faktör yükleri

\begin{tabular}{|c|c|c|c|}
\hline $\begin{array}{l}\mathrm{n}=294, \\
\text { Madde no }\end{array}$ & Madde İçerik & $\begin{array}{c}\text { MAÖ- } \\
\text { ÇS }\end{array}$ & $\begin{array}{c}\text { Faktörlerin } \\
\text { Açıkladığı } \\
\text { Varyans } \\
(\%) \\
\end{array}$ \\
\hline MPÖ-ÇS_11 & İnsanlar mükemmel performans göstermediğinde onları eleştiririm. & ,71 & \\
\hline MPÖ-ÇS_12 & İnsanlar mükemmel performans göstermediğinde onlar hakkında olumsuz düşünürüm. & ,71 & \\
\hline MPÖ-ÇS_9 & Diğerleri mükemmel performans göstermediğinde onlar hakkında olumsuz düşünürüm. & ,68 & \\
\hline MPÖ-ÇS_8 & Mükemmel performans göstermediğimde insanlar beni eleştirir. &, 57 & $\% 32.34$ \\
\hline MPÖ-ÇS_10 & Diğerlerinin performanslarından asla tatmin olmam. &, 55 & \\
\hline MPÖ-ÇS_1 & Mükemmel performans göstermediğimde kendime kızarım. &, 36 & \\
\hline MPÖ-ÇS_2 & Mükemmel performans göstermem için kendime baskı yaparım. &, 35 & \\
\hline
\end{tabular}
Temel Bileşenler Analizi (Principal Component Analysis)

Tablo 5'te veri setine ilişkin gerçekleştirilen faktör analizi sonuçları yer almaktadır. Buna göre 294 çocuk sporcu ile gerçekleştirilen AFA sonuçları incelendiğinde maddelerin faktör yük değerlerinin “.35 -.71” aralığında yük değerlerine sahip olduğu görülmektedir. Maddelerin açıkladığı varyans \% 32.34 olduğu belirlenmiştir. Bu sonuçlar MPÖ-ÇS'nin tek faktörlü yapıyı desteklediğini göstermektedir. Böylece MPÖ-ÇS için beş maddelik tek faktörlü yapının doğrulanması için Doğrulayıcı Faktör Analizi (DFA) yapılmıştır. Tek faktörlü yapıya ilişkin Doğrulayıcı Faktör Analizi (DFA) sonuçlarının yorumlanmasında genel kabul görmüş uyum indekslerine dikkate alınmıştır.

MPÖ-ÇS modeline ilişkin yol diagramı, uyum indeksleri ve modele ilişkin değerler Şekil 2 ve Tablo 6'da sunulmuştur.

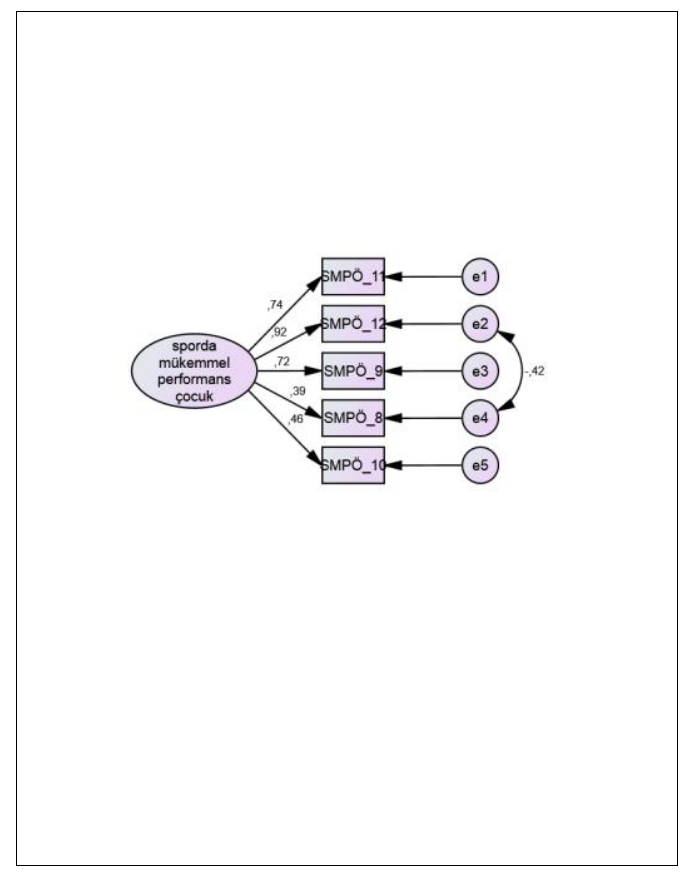

Şekil 2. MPÖ-ÇS’nin yol diagramı 
Esentaş, M., Güzel, P., ve Yavaş Tez, Ö. (2020). Sporda Mükemmel Performans ölçeği’nin (PPS-S) çocuk ve yetişkin sporcular için geçerlik ve güvenirliğinin incelenmesi: Kısa form. Ulusal Spor Bilimleri Dergisi, 4(1), 18-34.

Tablo 6. MPÖ-ÇS'nin uyum indeksleri ile standart uyum değerleri (Schumacher ve Lomax, 1996; Schermelleh, Engel ve Moosbrugger, 2003: 23-74).

\begin{tabular}{l|ccc}
\hline Uyum İndeksi & Mükemmel Uyum & Kabul Edilebilir Uyum & $\begin{array}{c}\text { MAÖ-ÇS Uyum } \\
\text { Indeksleri }\end{array}$ \\
\hline $\mathbf{x}^{\mathbf{2}} / \mathbf{s d}$ & $0-3$ & $3-5$ & $\mathbf{1 . 5 0}$ \\
CFI & $.95 \leq \mathrm{CFI} \leq 1.00$ & $.90 \leq \mathrm{CFI}<.95$ & $\mathbf{. 9 9}$ \\
GFI & $.90 \leq \mathrm{GFI} \leq 1.00$ & $.85 \leq \mathrm{GFI}<.90$ & $\mathbf{. 9 9}$ \\
AGFI & $.90 \leq \mathrm{AGFI} \leq 1.00$ & $.85 \leq \mathrm{AGFI}<.90$ & $\mathbf{. 9 7}$ \\
NFI & $.95 \leq \mathrm{NFI} \leq 1.00$ & $.90 \leq \mathrm{NFI}<.95$ & $\mathbf{. 9 8}$ \\
TLI & $.90 \leq \mathrm{TLI} \leq 1.00$ & $.85 \leq \mathrm{TLI}<.90$ & $\mathbf{. 9 8}$ \\
RMSEA & $.00 \leq \mathrm{RMSEA} \leq .05$ & $.05<\mathrm{RMSEA} \leq .10$ & $\mathbf{. 0 4}$ \\
\hline
\end{tabular}

Tablo 6 incelendiğinde MPÖ-ÇS'nin uyum indeksleri, standart uyum indeksleri ile karşılaştırıldığında MPÖ-ÇS'nin mükemmel değer aralıkları içerisinde olduğu belirlenmiştir. MPÖ-ÇS'ye ilişkin maddelerin faktör yük değerlerinin .38 ile .92 arasında değiştiği görülmektedir. Buna göre MPÖ-ÇS'nin 5 maddelik azaltılmış madde sayısı orijinal formdan farklı olarak tek faktörlü yapıyı desteklediği ve çocuk sporcular için tek faktörlü yapısının Türk örnekleminde doğrulandığı belirlenmiştir.

Ayrıca MPÖ-ÇS'nin madde-toplam korelasyonları, yakınsak ve ıraksak geçerlik için Açıklanan Ortalama Varyans (AVE), Açıklanan Ortalama Varyansın Karekökü (VAVE) ile Yapı Güvenirliği (CR) değerleri hesaplanmıştır. Analiz sonuçları Tablo 7'de sunulmuştur.

Tablo 7. Mükemmel Performans Ölçeği Çocuk Sporcular (MPÖ-ÇS) için gerçekleştirilen dfa sonucuna göre faktör korelasyon ilişkisi, faktörler arası korelasyon değerlerinin karesi, AVE, $\sqrt{ }$ AVE ve CR değerleri

\begin{tabular}{|c|c|c|c|c|c|c|c|c|c|c|}
\hline & & 1 & 2 & 3 & 4 & 5 & 6 & AVE & $\sqrt{ } \mathbf{A V E}$ & $\mathbf{C R}$ \\
\hline 1.MPÖ-ÇS-11 & $\mathbf{r}$ & 1 &, $67^{* *}$ &, $50^{* *}$ &, $30^{* *}$ &, $33^{* *}$ &, $77^{* *}$ & 0.64 & 0.80 & 0.85 \\
\hline 2.MPÖ-ÇS-12 & $\mathbf{r}$ & & 1 &, $66^{* *}$ &, $20^{* *}$ &, $40^{* *}$ &, $78^{* *}$ & & & \\
\hline 3.MPÖ-ÇS-9 & $\mathbf{r}$ & & & 1 &, $24^{* *}$ &, $39^{* *}$ &, $75^{* *}$ & & & \\
\hline 4.MPÖ-ÇS-8 & $\mathbf{r}$ & & & & 1 &, $22^{* *}$ &, $60^{* *}$ & & & \\
\hline 5.MPÖ-ÇS-10 & $\mathbf{r}$ & & & & & 1 &, $67^{* *}$ & & & \\
\hline 6.MAÖ-ÇS TOPLAM & $\mathbf{r}$ & & & & & & 1 & & & \\
\hline
\end{tabular}

Tablo 7'de MPÖ-ÇS'ye ilişkin madde-toplam korelasyon, Açıklanan Ortalama Varyans (AVE) ve Yapı Güvenirliği (CR) değerleri verilmiştir. MPÖ-ÇS'ye ilişkin madde-toplam korelasyon katsayılarının 0.60 ile 0.78 arasında değiştiği görülmektedir. MPÖ-ÇS'ye ilişkin AVE değeri $0.64, \sqrt{ }$ AVE değeri 0.80 ve CR değeri 0.85 olarak hesaplanmıştır. Literatürde AVE değerinin $(0.50<\ldots)$ ve CR değerinin $(0.70<\ldots)$ olması beklenmektedir (Hair ve diğ., 2009). 
Literatürde 1raksak geçerlik için benimsenen yaklaşım ölçüm modelinde yer alan korelasyon değerlerinin 0.90'nın üzerinde olmaması gerektiği (Kline, 2010) ve bu değerlerin hesaplanmasının ise AVE değerinin karekökü alınarak ortaya çıkan değerin korelasyon katsayılarından daha yüksek olması gerektiği ifade edilmiştir (Fornell and Larcker, 1981). Bu doğrultuda MPÖ-ÇS için hesaplanan ıraksak geçerlik değerlerinin kriter olarak belirlenen 0.90 değerinin altında olduğu belirlenmiştir. Buna göre yapılan hesaplamalar sonrasında ölçeğe ilişkin AVE ve CR değerlerinin minimum eşik sınırı değerlerinin üstünde ve AVE değerinin karekökünün ise maksimum eşik sınırı değerlerinin altında olması ölçüm modellinin kabul edilebilir düzeyde yakınsak ve ıraksak geçerliğe sahip olduğunun kanıtı niteliğindedir.

\section{Güvenirlik}

MPÖ-ÇS'nin güvenirliği için iç tutarlılık katsayıları Cronbach Alpha ve iki yarı test güvenirlik (Split-Half) yöntemleriyle hesaplanmıştır. Literatürde Büyüköztürk (2010) tarafından Cronbach Alpha güvenirlik katsayısının 0.70 ve üzerinde olmasının ölçek güvenilirliği için yeterli kabul edilebileceği ifade edilmiştir. Bu doğrultuda MPÖ-ÇS için Alpha katsayısı 0.74 olarak hesaplanması ölçme aracının güvenilir olarak kabul edilebileceğini göstermiştir. Araştırmada zaman ve uygulama kolaylığı açısından iki yarı test güvenirliği tercih edilmiş ve bu doğrultuda ölçek maddeleri rastlantısal şekilde ikiye ayrılarak formül yardımıyla [r Test $=(2 \mathrm{r} / 1+\mathrm{r}) ; \mathrm{r}=$ testin yarısına ait korelasyon katsayısı] güvenirlik katsayısı hesaplanmıştır (Seçer, 2013). Bu doğrultuda MPÖ-ÇS'nin Spearman-Brown değeri 0.88 ve Guttman değeri 0.82 olarak hesaplanmıştır. Bu değerler bize ölçeğin kabul edilebilir düzeyde ve güvenilir olduğunu göstermektedir. Analiz sonuçları Tablo 9'da sunulmuştur.

Tablo 8. Beş maddelik MPÖ-ÇS'nin iç tutarlık (Cronbach Alpha) ve iki yarı test (Split-Half) güvenirlik değerleri, madde numaraları ve içerikleri

\begin{tabular}{|c|c|c|c|c|}
\hline & Madde Numaraları ve İçerikleri & $\begin{array}{l}\text { Spearman- } \\
\text { Brown }\end{array}$ & $\begin{array}{c}\text { Guttma } \\
\text { n }\end{array}$ & $\begin{array}{l}\text { Cronbach } \\
\text { Alpha (a) }\end{array}$ \\
\hline $\begin{array}{c}\text { Mükemmel } \\
\text { Performans Ölçeği- } \\
\text { Yetişkin Sporcular } \\
\text { (MPÖ-ÇS) } \\
(\mathbf{8 , 9 , 1 0 , 1 1 , 1 2 )}\end{array}$ & $\begin{array}{l}\text { MPÖ-ÇS-11 (İnsanlar mükemmel performans göstermediğinde onları } \\
\text { eleştiririm.) } \\
\text { MPÖ-ÇS-12 (İnsanlar mükemmel performans göstermediğinde onlar } \\
\text { hakkında olumsuz düşünürüm.) } \\
\text { MPÖ-ÇS-9 (Diğerleri mükemmel performans göstermediğinde onlar } \\
\text { hakkında olumsuz düşünürüm.) } \\
\text { MPÖ-ÇS-8 (Mükemmel performans göstermediğimde insanlar beni } \\
\text { eleştirir.) } \\
\text { MPÖ-ÇS-10 (Diğerlerinin performanslarından asla tatmin olmam.) }\end{array}$ & 0.88 & 0.82 & .74 \\
\hline
\end{tabular}

$\boldsymbol{\alpha}:$ Beş maddelik MPÖ-ÇS'nin Cronbach Alpha $(\alpha)$ değeri 


\section{TARTIŞMA VE SONUÇ}

Sporda Mükemmel Performans Ölçeği (PPS-S), geliştiren araştırmacılar (Hill, Appleton ve Mallinson, 2016) tarafından ölçeğin ileriki çalışmalar için yetişkinler ve diğer performans bağlamlarında (örneğin, eğitim ve iş) kullanımı için geçerlik ve güvenirlik çalışmalarının yapılması istenmiştir. Bu nedenle mevcut araştırmada Mükemmel Performans Ölçeği’nin yetişkin ve çocuk sporcular üzerinde geçerlik ve güvenirlik çalışması yapılmış ve ölçeğin her iki kısa formu için gerekli olan prosedürler bildirilmiştir.

Literatürde SOPP'un (kendine yönelik mükemmel performans) motivasyon, performans ve psikolojik zorluklar için bir kırılganlık faktörü olduğu düşünülmektedir (Flett ve Hewitt, 2005, 2006). Bu bağlamda mükemmeliyetçilik boyutlarının davranışı olumlu ya da olumsuz etkileme potansiyelini anlamak, özellikle sporcuların mükemmel olmasını gerektiren rekabet ortamlarında önemli rol oynamaktadır. Bu da belirli ölçme araçlarının bu durumun daha iyi anlaşılmasına katkı sağlayacaktır.

Sporda Mükemmel Performans Ölçeği’nin (PPS-S) sporcular üzerinde farklı kültürlerde adaptasyon çalışmaları incelendiğinde Angelo ve diğer. (2019) yaşları 15 ile 16 yaşında 953 sporcu ile Brazilyan versiyonu için geçerlik ve güvenirlik çalışması yapmıştır. Yapılan çalışmada ölçeğin Açımlayıcı Faktör Analizi (AFA) yapılmadan orijinal formdaki faktör yapısı doğrudan alınarak Doğrulayıcı Faktör Analizi (DFA) yapılmıştır. Analiz sonucunda ölçek, 3 faktör ve 9 madde ile Brazilyan versiyonu için doğrulanmıştır $(\chi 2=116.15 \mathrm{p}<0.001$, $\mathrm{RMSEA}=0.063, \mathrm{GFI}=0.974, \mathrm{AGFI}=0.961, \mathrm{NFI}=0.937, \mathrm{CFI}=0.928, \mathrm{NNFI}=915, \chi 2 / \mathrm{gl}$ $=4.83$ ). Ölçeğin faktör yapısı ve madde sayısı ile birlikte tatmin edici uyum indekslerine sahip olduğu doğrulansa da raksak geçerlik ile birleşik güvenirlik değerleri tatmin edici düzeyde olmaması sebebi ile ölçeğin Brazilyan versiyonunun dikkatli bir şekilde kullanılması ve ölçeğin psikometrik özelliklerinin yeniden incelenmesi gerektiği araştırmacılar tarafından bildirilmiştir. Kaldı ki özellikle ölçeklerin uyarlanmasında faktör analitik tekniklerle maddelerin incelenmesi çok daha fazla özen gerektiren bir iştir. Psikolojik değişkenlerin çoğu kültüre bağımlıdır ve bu nedenle kültürlerle (sadece başka kültürlere değil, aynı kültür için de farklı hedef gruplara da uyarlama çalışması yapılır) "çeviri değil” "uyarlama” çalışmaları yapılır. $\mathrm{Bu}$ ne demek? Bir araştırmacının ölçekleri geliştirirken ya da uyarlarken kendi kültürel yapısını dikkate almasıdır. Diyelim ki bir kültürde bir ölçme aracı geliştirildi ve o kültürde o ölçe aracının yapısı 3 faktörlü olarak belirlendi. Farklı bir kültürden bir araştırmacı bu ölçeği kendi kültürü için kullanmak ister ve doğrudan ölçeğin çevirisini yapıp aynı yapı üzerinden doğrulama aşamasına geçer ise (doğrulayıcı faktör analizi) hata yapmış olacaktır. Çünkü o kültürde 3 faktörlü bir yapısı olan bir ölçme aracının bizde 4 faktörlü veya 2 faktörlü çıkma hatta ölçeğin doğrulanmama ihtimali vardır ve bu kültür için önemli bir bilgi taşır. $\mathrm{Bu}$ gibi durumlarda da kendi kültürümüzdeki yapı dikkate alınmalı, isimlendirme ve puanlama ona göre önerilmelidir. Ne yazık ki ulusal ve uluslararası literatürdeki çalışmalar incelendiğinde farklı faktör yapısı bulunmasına rağmen, orijinalindeki gibi kullanmak için "zorlama" bir şekilde faktör yapısı denkleştirilmeye çalışılmaktadır. Bu da kültüre uyarlama esprisini ortadan kaldırmaktadır (Balcı ve Yavaş Tez, 2019). 
Bu koşullar dikkate alınarak MPÖ-YS ve MPÖ-ÇS ölçeklerinin faktör yapılarına ilişkin genel bir değerlendirilme yapıldığında; her iki ölçeğin de Türk kültürü için faktör analizi (AFA) sonuçları bize 3 faktörlü yapısının uygun bir yapı olmadığını; her iki ölçme aracı için de (MPÖ-YS ve MPÖ-ÇS) tek faktörlü bir yapıyı desteklediğini göstermiştir. Her iki ölçme aracında da faktörlerin orijinal formda yer alan 3 alt boyuttaki maddeler arasından toplandığ dikkat çekmektedir. MPÖ-YS tek faktörlü yapısı altında toplamda altı madde var iken MPÖÇS beş madde yer almaktadır. Altı maddelik tek faktörlü MPÖ-YS ile beş maddelik tek faktörlü MPÖ-ÇS'nin faktör yapıları incelendiğinde MPÖ-YS'ye ilişkin sonuçların mükemmel ve kabul edilebilir uyum indekslerine $(\chi 2 / \mathrm{sd}=2.21$, RMSEA $=0.07$, GFI $=0.97$, AGFI $=0.92, \mathrm{NFI}=0.96, \mathrm{CFI}=0.97$, AGFI $=0.92$; MPÖ-ÇS'nin ise mükemmel uyum indekslerine sahip olduğu belirlenmiştir $(\chi 2 / \mathrm{sd}=1.50$, RMSEA $=0.04$, GFI $=0.99$, AGFI $=$ 0.97, $\mathrm{NFI}=0.98, \mathrm{CFI}=0.99, \mathrm{AGFI}=0.97)$.

Angelo vd., (2019) Brazilyan formunda uyum indeksleri yeterli düzeyde bulunurken yakınsak ve 1raksak geçerlik değerlerinin tahmin edici olmadığ 1 vurgulanmıştır. Mevcut araştırmada MPÖ-YS ve MPÖ-ÇS'nin her ikisi için yapılan hesaplamalar sonrasında MPÖ-YS ve MPÖÇS'nin madde-toplam korelasyon katsayılarının MPÖ-YS için 0.58 ile 0.81 arasında değiştiği; MPÖ-ÇS için 0.60 ile 0.78 arasında değiştiği belirlenmiştir. Yakınsak (convergent) geçerlik değerlerinin minimum eşik sınırın üzerinde olduğu belirlenirken (MPÖ-YS, AVE= 0.62, $\mathrm{CR}=0.86$; MPÖ-ÇS, $\mathrm{AVE}=0.64, \mathrm{CR}=0.85$ ); 1raksak (divergent) geçerlik için hesaplanan AVE değerinin karekök ortalamalarının da maksimum eşik sınırın altında olmasının her iki ölçüm modellerinin kabul edilebilir düzeyde yakınsak ve ıraksak geçerliğe sahip olduklarının kanıtı niteliğindedir (MPÖ-YS, AVE=0.62, $\sqrt{ } \mathrm{AVE}=0.79$; MPÖ-ÇS, $\mathrm{AVE}=0.64, \sqrt{ } \mathrm{AVE}=0.80$ ).

Elde edilen sonuçlara göre, MPÖ-YS ve MPÖ-ÇS'nin rekabete ilişkin sporlar ile uğraşan çocuk sporcu ve yetişkin sporcuların mükemmel performansa ilişkin düzeylerinin belirlenebilmesi için kullanılabilecek geçerli ve güvenilir ölçme aracı oldukları belirlenmiştir.

\section{ÖNERILER}

Sporda mükemmel performansın belirleyici özelliklerinin ortaya çıkarılması belki de bir sporcunun hayatının en önemli yönüdür. $\mathrm{Bu}$ nedenle ölçeğin araştırmacılar ve antrenörler tarafından alanda kullanılması mükemmeliyetçiliğin hangi durumlarda sporcuyu zorluklara karşı savunmasız hale getirdiğini anlamaya yardımcı olabilir ve psikolojik eğitimde ele alınması gereken stratejiler için ipuçları sunabilecektir. Dahası, bu tür bilgiler sadece Türkiye'de değil, aynı zamanda kültürel araştırma yapma olasılığı üzerinde spor mükemmeliyetçiliği hakkında daha fazla araştırmaya izin verecektir. Bu nedenle, MPÖ-YS ve MPÖ-ÇS'nin Türk nüfusunda performans mükemmeliyetçiliğini değerlendirmek için bir ölçme aracı sunduğu düşünülmelidir. Bu ölçme araçları Türkiye'de Mükemmel Performans Ölçeği Yetişkin Sporcular (MPÖ-YS) ve Mükemmel Performans Ölçeği Çocuk Sporcular (MPÖ-ÇS) olarak adlandırılacaktır. 
Esentaş, M., Güzel, P., ve Yavaş Tez, Ö. (2020). Sporda Mükemmel Performans ölçeği'nin (PPS-S) çocuk ve yetişkin sporcular için geçerlik ve güvenirliğinin incelenmesi: Kısa form. Ulusal Spor Bilimleri Dergisi, 4(1), 18-34.

\section{KAYNAKLAR}

Angelo, D. L., Neves, A. N., Correa, M., Sermarine, M., Zanetti, M. C., \& Brandão, M. R. F. (2019). Psychometric properties of the perfectionism for sports performance scale (PPS-S) for the Brazilian context. Cuadernos de Psicología del Deporte, 19(2), 1-11. https://www.researchgate.net/publication/332798716.

Aşçı, F. H., Çağlar, E., Eklund, R. C., Altıntaş, A., ve Jackson, S. (2007). Durumluk ve sürekli optimal performans duygu durum-2 ölçekleri'nin uyarlama çalışması. Spor Bilimleri Dergisi, 18(4), 182-196.

Balcı, V., ve Yavaş Tez, Ö. (2019). Serbest zaman nostalji ölçeği (sznö): geçerlik ve güvenirlik çalışması. Sportif Bakış: Spor ve Ĕgitim Bilimleri Dergisi, 6(2), 218-229. DOI: 10.33468/sbsebd.99.

Bieling, P. J., Israeli, A. L., \& Antony, M. M. (2004). Is perfectionism good, bad, or both? Examining models of the perfectionism construct. Personality and Individual Differences, 36(6), 1373-1385. DOI:10.1016/S0191-8869(03)00235-6.

Chang, E. C. (2003). On the perfectibility of the individual: going beyond the dialectic of good versus evil. American Psychological Association, 16(3),125-144. DOI:10.1037/10614-008.

Çepikkurt, F. (2011). Üniversiteli hentbolcuların mükemmeliyetçilik ve kaygl düzeyleri ile başarı hedefleri ve müsabaka sonuçlarına yaptıkları yükleme biçimleri arasındaki ilişkinin incelenmesi. (Yayınlanmamış Doktora Tezi). Çukurova Üniversitesi Sağlık Bilimleri Enstitüsü, Adana.

Çepikkurt, F., ve Yazgan, İ. B. (2012). Mükemmeliyetçilik ve başarı hedeflerinin hentbolcuların müsabaka öncesi yaşadıkları durumluk kaygıyı belirlemedeki rolü. Spormetre Beden Eğitimi ve Spor Bilimleri Dergisi, 10(2), 43-51.

Enns, M. W., \& Cox, B. J. (2002). The nature and assessment of perfectionism: a critical analysis. American Psychological Association,15(1), 27-33. DOI:10.1037/10458-002.

Ermiş, E. (2019). Analysis of amateur soccer players leadership levels in terms of their positions. Journal of Education and Training Studies, 7(6), 24-32. DOI: 10.11114/jets.v7i6.4125.

Flett, G. L., \& Hewitt, P. L. (2002). Perfectionism and maladjustment: an overview of theoretical, definitional, and treatment issues. American Psychological Association, 3(7), 5-31. DOI:10.1037/10458-001.

Flett, G. L., \& Hewitt, P. L. (2005). The perils of perfectionism in sports and exercise. Current Directions in Psychological Science, 14(1), 14-18. DOI:10.1111/j.0963-7214.2005.00326.x.

Flett, G. L., \& Hewitt, P. L. (2006). Positive versus negative perfectionism in psychopathology: A comment on Slade and Owens's dual process model. Behavior Modification, 30(4), 472-495. DOI: $10.1177 / 0145445506288026$.

Fornell, C., \& Larcker, D. F. (1981). Evaluating Structural Equation Models with Unobservable Variables and Measurement Error. Journal of Marketing Research, 18(1), 39-50. DOI: 10.2307/3151312.

Gould, D., Dieffenbach, K., \& Moffett, A. (2002). Psychological characteristics and their development in Olympic champions. Journal of Applied Sport Psychology, 14(3), 172-204. 10.1080/10413200290103482.

Gözmen, A., ve Aşçı, F. H. (2016). Sporcularda Optimal Performans Duygu Durumunun Yordanmasında Beş Faktörlü Kişilik Özelliklerinin ve Mükemmeliyetçiliğin Rolü, Spor Bilimleri Dergisi, 27(1), 40-48.

Gutmann, A. (2002). The olympics: A history of the modern games. Urbana: University of Illinois Press.

Gümüşoğlu, Ö., ve Aşçı H. (2020). Yetişkin sporcularda belirsizliğe tahammmülsüzlüğün yordanmasında mükemmeliyetçilik ve zihinsel dayanıklılığın rolü. Spormetre Beden Eğitimi ve Spor Bilimleri Dergisi, 18(1), 96-110. 
Esentaş, M., Güzel, P., ve Yavaş Tez, Ö. (2020). Sporda Mükemmel Performans ölçeği'nin (PPS-S) çocuk ve yetişkin sporcular için geçerlik ve güvenirliğinin incelenmesi: Kısa form. Ulusal Spor Bilimleri Dergisi, 4(1), 18-34.

Güzel, P., ve Özbey, S. (2013). Promotion of olympic values based on olympic solidarity programs. International Journal of Academic Research, 5(3), 277-288. DOI: 10.7813/2075-4124.2013/5-3/B.43.

Güzel, P., ve Özbey, S. (2009). Olimpik eğitim programlarına genel bakış: IOC 46. Uluslararası Genç Kat1limcilar Oturumu, Olympia. Uluslararasi Insan Bilimleri Dergisi, 6(1), 886-898. DOI: 10.14687/ijhs.v6i1.731.

Güzel, P., Özbey, S., ve Noordegraff, M. A. (2012). Olimpik eğitimin yaygınlaştırılmasında üniversite oyunlarının etkileri. Uluslararası Insan Bilimleri Dergisi, 9(1), 296-321. DOI: 10.14687/ijhs.v9i1.2099.

Güzel, P., ve Özbey, S. (2012). IOC olympıc solidarity programs and Turkish Natıonal Olympic Committees's (TMOK) Implementations. Pamukkale Spor Bilimleri Dergisi, 3(1), 30-41.

Güzel, P., ve Çelebi, M. (2017). Herkes için spor kapsamında olimpik dayanışma programları, olimpizm ve olimpik hareket, (Çev. Selhan ÖZBEY). Ankara: Nobel.

Hair, J. F., Black, W. C., Babin, B. J., \& Anderson, R. E. (2009). Multivariate data analysis. NJ: Prentice Hall.

Hewitt, P. L., Flett, G. L., Turnbull-Donovan, W., \& Mikail, S. F. (1991). The Multidimensional Perfectionism Scale: Reliability, validity, and psychometric properties in psychiatric samples. Psychological Assessment: A Journal of Consulting and Clinical Psychology, 3(3), 464. DOI:10.1037/10403590.3.3.464.

Hewitt, P. L., \& Flett, G. L. (1991). Perfectionism in the self and social contexts: Conceptualization, assessment, and association with psychopathology. Journal of Personality and Social Psychology, 60(3), 456-470. DOI:10.1037/0022-3514.60.3.456.

Hill, A. P., Appleton, P. R., \& Mallinson, S. H. (2016). Development and initial validation of the Performance Perfectionism Scale for Sport (PPS-S). Journal of Psychoeducational Assessment, 34(7), 653-669. http://ray.yorksj.ac.uk/id/eprint/1708/.

Hill, R. W., Huelsmann, T. J., Furr, R. M., Kibler, J., Vicente, B. B., \& Kennedy, C. (2004). A new measure of perfectionism: The Perfectionism inventory. Journal of Personality Assessment, 82(1), 80-91. DOI: 10.1207/s15327752jpa8201_13.

Hurley, M. (2011). Futbol oynuyorum: Defans (Çev: Neşe Akın). İstanbul: Caretta Çocuk Yayınları.

Jones, G. J., Carlton, T., Hyun, M., Kanters, M., \& Bocarro, J. (2020). Assessing the contribution of informal sport to leisure-time physical activity: A New perspective on social innovation. Managing Sport and Leisure, 25(3), 161-174. DOI:10.1080/23750472.2019.1620627.

Karasar, N. (2013). Bilimsel araştırma yöntemi. Ankara: Nobel.

Kline, R. B. (2011). Principles and Practice of Structural Equation Modeling. New York: The Guilford Press.

Kurudirek, M. I. (2017). Perfectionism and achievement goals in professional Turkish ice hockey players. TURAN-SAM, 9(36), 392-400.

Kocadağ, N. H. (2019). Adolesan sporcuların tükenmişliğinin belirlenmesinde algılanan ebeveyn mükemmeliyetçiliği ve güdüsel ikliminin rolü. Yüksek Lisans Tezi, Marmara Üniversitesi, Sağlık Bilimleri Enstitüsü, Beden Eğitimi ve Spor Anabilim Dalı, İstanbul.

Krathwohl, D. (1997). Methods of educational and social science research. Longman: New York.

Küçük, V., ve Koç, H. (2004). Psiko-sosyal gelişim süreci içersinde insan ve spor ilişsisi. Dumlupınar Üniversitesi Sosyal Bilimler Dergisi, 9(1), 211-223. 
Esentaş, M., Güzel, P., ve Yavaş Tez, Ö. (2020). Sporda Mükemmel Performans ölçeği'nin (PPS-S) çocuk ve yetişkin sporcular için geçerlik ve güvenirliğinin incelenmesi: Kısa form. Ulusal Spor Bilimleri Dergisi, 4(1), 18-34.

Urfa, O., ve Aşçı, F. H. (2019). Spor duygu ölçeği: geçerlik ve güvenirlik çalışması. Spormetre Beden Ĕ̆itimi ve Spor Bilimleri Dergisi, 17(4), 42-55.

Özdemir, İ. (2019). Takım sporları ile uğraşan yetişkin sporcuların prososyal ve antisosyal davranışlarının belirlenmesinde mükemmeliyetçilik ve başarı. Yüksek Lisans Tezi, Marmara Üniversitesi, Sağlık Bilimleri Enstitüsü, Beden Eğitimi ve Spor Anabilim Dalı, İstanbul.

Salaheldeen, H. M. (2010). Olympic values and multiculturalism. IOA, 17th International Seminar on Olympic Studies for Postgraduate Students, 1-30 July, 2009. Olympia: The International Olympic Committee and International Olympic Academy.

Snedden, T. R., Scerpella, J., Kliethermes, S. A., Norman, R. S., Blyholder, L., Sanfilippo, J., ... \& Heiderscheit, B. (2019). Sport and physical activity level impacts health-related quality of life among collegiate students. American Journal of Health Promotion, 33(5), 675-682. DOI: 10.1177/0890117118817715.

Suddarth, B. H., \& Slaney, R. B. (2001). An investigation of the dimensions of perfectionism in college students. Measurement and Evaluation in Counseling and Development, 34(3),157-165. DOI:10.1080/07481756.2002.12069032.

Türk Dil Kurumu. (2020). Erişim tarihi: 18.04.2020 https://sozluk.gov.tr/

Unutmaz, V., ve Gençer, T. (2017). Antrenör yeterlilik ölçeği II'nin Türkçe uyarlama çalışması. Spor Bilimleri Araştırmaları Dergisi, 2(2), 69-78.

WHO (World Health Organization). (2015). World report on ageing and health. World Health Organization.

Yetim, A. (2011). Sosyoloji ve spor. Ankara: Topkar.

Yiyit, S. (2017). Spor etkinliklerine katılımın psikolojik faydaları üzerine bir değerlendirme. Uluslararası Spor Bilimleri Dergisi, 3(1), 17-22.

Bu eser Creative Commons Atıf-GayriTicari 4.0 Uluslararası Lisansı ile lisanslanmıştır. 